\title{
Chemical Lipid Biomarkers in Children Exposed to Second Hand Smoking
}

\author{
MONICA STELUTA MARC ${ }^{1}$, IOANA MIHAIELA CIUCA ${ }^{2 *}$, LAVINIA MOLERIU $^{3}$, \\ STELA IURCIUC ${ }^{4}$, ANIKO MARIA MANEA ${ }^{5}$, VLADIANA TURI ${ }^{6}$, GEORGIANA DAMIAN ${ }^{7}$, \\ PAULA MARIAN ${ }^{8}$, ESTERA BOERIU ${ }^{9}$ \\ ${ }^{1}$ Victor Babes University of Medicine and Pharmacy, Pulmonology Department, 2 Eftimie Murgu Sq, 300041, Timisoara, \\ Romania \\ ${ }^{2}$ Victor Babes University of Medicine and Pharmacy, Pediatric Department, 2 Eftimie Murgu Sq 300041, Timisoara, \\ Romania \\ ${ }^{3}$ Victor Babes University of Medicine and Pharmacy, Department of Functional Sciences, Medical Informatics and \\ Biostatistics Discipline, 2 Eftimie Murgu Sq 300041, Timisoara, Romania \\ ${ }^{4}$ Victor Babes University of Medicine and Pharmacy, Department of Cardiology, 2 Eftimie Murgu Sq. 300041, Timisoara, \\ Romania \\ ${ }^{5}$ Victor Babes University of Medicine and Pharmacy, Neonatology Department, 2 Eftimie Murgu Sq. 300041, Timisoara, \\ Romania \\ ${ }^{6}$ Victor Babes University of Medicine and Pharmacy, Faculty of Medicine, Cardiology Department, Internal Medicine, \\ Preventive Cardiology and Cardiovascular Rehabilitation Discipline, 2 Eftimie Murgu Sq. 300041, Timisoara, Romania \\ ${ }^{7}$ Victor Babes University of Medicine and Pharmacy, Cardiology Department, Internal Medicine, Preventive Cardiology \\ and Cardiovascular Rehabilitation Discipline, 2 Eftimie Murgu Sq. 300041, Timisoara, Romania \\ ${ }^{8}$ University of Oradea, Faculty of Medicine and Pharmacy, Department of Medical Disciplines, 5 Armatei Romane Str., \\ 410087, Oradea, Romania \\ ${ }^{9}$ Victor Babes University of Medicine and Pharmacy, Pediatric Department, Discipline Pediatrics 3, 2 Eftimie Murgu Sq., \\ 300041, Timisoara, Romania
}

\begin{abstract}
Smoking is a major global public health problem, a trigger for chronic diseases and a significant preventable risk factor of global death. Smoking represents a major cardiovascular risk factor for adults, but the effect of passive smoking in children is not well established. The study evaluated the relationship between serum biomarkers such as lipids, cholesterol, triglycerides and passive smoking in children. We noticed that passive smoking creates alterations in HDL-cholesterol which decreased significantly in the presence of passive smoking.
\end{abstract}

Keywords: second-hand smoking, children, lipid profile, HDL-cholesterol

\section{Introduction}

With the growing exposure to smoking in children was reported worldwide, in 2016, an estimated one-third of females, one-fifth of males globally and approximately $66 \%$ of children aged 3-11 years were exposed to second-hand smoke (SHS). The prevalence of exposure to second-hand smoke in restaurants varies among European Union member states, between $<10 \%$ to nearly $80 \%$ in Greece [1]. While the pulmonary consequences of SHS exposure are clinically apparent in childhood, the cardiovascular effects of SHS exposure are occult but substantial [2] It appears that SHS exposure in early childhood, even in utero, can cause persistent lipoprotein changes later in life [3], increased incidence of obesity [4], lower high-density lipoprotein cholesterol (HDL C) levels in children [5]. Chemicals from tobacco second-hand smoke have several bad effects on various cardiovascular diseases, including coronary artery disease, ischemic stroke, non-traumatic subarachnoid haemorrhage [8], platelet activation, stimulation of the coagulation cascade [9]. Kalishadi and colleagues [10 showed that both smoking and exposure to smoke are associated with an increased risk of cardiometabolic risk factors and metabolic syndrome in adolescents.

$\overline{\text { *email: ciuca.ioana@umft.ro }}$ 
The nicotine induces lipolysis via catecholamine action at $\beta$-adrenoreceptors, increasing plasma free fatty acid concentrations, which could result in enhanced synthesis of LDL and lowering of HDL cholesterol. Additionally may enhance insulin resistance via increased levels of insulin-antagonistic hormones (cortisol, catecholamine, and growth hormone) and also directly activating AMP-activated protein kinase in adipose tissue mediating the effect of nicotine [11] on insulin sensitivity [12].

\section{Material and methods}

From the patients participating in to a study for cardiovascular risk, non-smokers were invited to participate in this study extension. Patients were grouped by the leves of exposure, based on the parental smoking habit: group 1: non-smokers / non-smoking parents (controls), group 2: passive smoking / one smoking parent and group 3: passive smoking / two smoking parents, after filling a questionnaire about smoking habits in the family.

The aim of study was to assess the levels of lipid biomarkers used for cardiovascular risk like total cholesterol, HDL-cholesterol, LDL-cholesterol, total lipid and triglycerides (TG) in relation to smoking exposure in children. The following chemical methods were used to obtain the serum levels of the mentioned parameters: colorimetric Rappaport method for cholesterol and its fractions-HDL, LDL; for triglycerides the colorimetry for sodium periodate, lipids were dosed by tubidimetry. For the statistical analysis, descriptive statistics and mean and standard deviations were calculated; ANOVA One-way test was applied for the relation between the biochemical parameters and smoking exposure. The statistical significance threshold was set at $\alpha=0.05$. Statistical analysis was performed using the Microsoft Excel and SPSSv17 software.

\section{Results and discussions}

In this study, 97 children, aged between 7 and 18 years old (median age 11.58), 57.73\% girls, were included; a larger percentage of $61.86 \%$ from urban environment. The serum levels of lipid biomarkers were dosed and the results showed the mean values, as follow: $4.12 \mathrm{~g} / \mathrm{l}$ for lipids, 162.61 for total cholesterol, a slightly increase median value considering the lower values reported by age [3]. HDLcholesterol had a $47 \mathrm{~g} / 1$ median value and LDL $2.68 \mathrm{~g} / 1$ and LDLC $101 \mathrm{~g} / \mathrm{l}$ (Table 1). No statistically significant differences were registred between groups in the lipids, trygliceride, total cholesterol and LDL-cholesterol levels, as it is showen in Table 1.

Table 1.Serum levels of lipidic profile: lipids, cholesterol, $\mathrm{TG}=$ triglycerides, $\mathrm{HDL}=$ high density lipoprotein cholesterol, LDL=low density lipoprotein cholesterol

\begin{tabular}{|c|c|c|c|c|c|}
\hline Statistics & Lipids & Cholesterol & TG & HDL & LDL \\
\hline Mean & 4.12 & 162.61 & 97.20 & 48.43 & 5.04 \\
\hline $\begin{array}{c}\text { Standard } \\
\text { Error }\end{array}$ & 0.27 & 2.89 & 8.59 & 1.14 & 2.22 \\
\hline Median & 5 & 161 & 82 & 47 & 2.68 \\
\hline Mode & 0 & 161 & 94 & 46 & 2.44 \\
\hline $\begin{array}{c}\text { Standard } \\
\text { Deviation }\end{array}$ & 2.68 & 28.42 & 84.57 & 11.26 & 21.86 \\
\hline $\begin{array}{c}\text { Sample } \\
\text { Variance }\end{array}$ & 7.20 & 807.80 & 7151.95 & 126.81 & 478.00 \\
\hline Kurtosis & 1.10 & -0.13 & 50.25 & -0.30 & 96.73 \\
\hline Skewness & -0.17 & 0.50 & 6.30 & 0.39 & 9.83 \\
\hline Range & 14.5 & 132 & 772 & 54 & 216.66 \\
\hline Minimum & 0 & 107 & 28 & 22 & 1.34 \\
\hline Maximum & 14.5 & 239 & 800 & 76 & 218 \\
\hline Sum & 399.85 & 15773 & 9428 & 4697.8 & 488.74 \\
\hline
\end{tabular}

An important percentage of $62.89 \%$ of children were "second hand smokers" because of their parents smoking habits and had an increase risk in future to smoke, compared to children with non- 
smoking parents [6]. A percentage of $5.16 \%$ of children had both parents smokers, while $37.11 \%$ had a single parent smoker and the group of controls included $57.73 \%$ patients. The values of lipids, cholesterol, LDL-cholesterol, HDL-cholesterol parameter $(\mathrm{p}=0.034)$ were obtained and the effect of the second hand smoking on the lipidic profile parameters was evaluated and showed an important consequence on the level of HDL-cholesterol. The level of the HDL fraction inchildren exposed to SHS from both parents was considerable decreased. This finding is similar with other study reffering to otherwise healthy children [5], with HDL low levels secondary to SHS, witch increase considerably the future cardiovascular risk for these children $[6,8,9]$.

Table 2. SHS effect on lipids, cholesterol, $\mathrm{TG}=$ triglycerides, HDL=high density lipoprotein cholesterol, LDL=low density lipoprotein cholesterol,

( One way ANOVA, p<0.05)

\begin{tabular}{|c|c|c|c|c|c|c|}
\hline Variables & Statistics & Sum of Squares & $\mathrm{df}$ & Mean Square & $\mathrm{F}$ & Sig. \\
\hline \multirow{3}{*}{ Lipids } & Between Groups & .093 & 2 & .046 & \multirow{3}{*}{0.006} & \multirow{3}{*}{0.994} \\
\hline & Within Groups & 690.827 & 94 & 7.349 & & \\
\hline & Total & 690.920 & 96 & & & \\
\hline \multirow{3}{*}{ Cholesterol } & Between Groups & 544.454 & 2 & 272.227 & \multirow{3}{*}{0.332} & \multirow{3}{*}{0.718} \\
\hline & Within Groups & 77004.659 & 94 & 819.199 & & \\
\hline & Total & 77549.113 & 96 & & & \\
\hline \multirow{3}{*}{ TG } & Between Groups & 18233.044 & 2 & 9116.522 & \multirow{3}{*}{1.282} & \multirow{3}{*}{0.282} \\
\hline & Within Groups & 668354.234 & 94 & 7110.151 & & \\
\hline & Total & 686587.278 & 96 & & & \\
\hline \multirow{7}{*}{ HDL } & Between Groups & 842.407 & 2 & 421.204 & \multirow{7}{*}{3.494} & \multirow{7}{*}{0.034} \\
\hline & Within Groups & 11331.440 & 94 & 120.547 & & \\
\hline & Total & 12173.847 & 96 & & & \\
\hline & Within Groups & 63261.589 & 94 & 672.996 & & \\
\hline & Total & 63273.241 & 96 & & & \\
\hline & Within Groups & 8719606.765 & 69 & 126371.113 & & \\
\hline & Total & 9069865.875 & 71 & & & \\
\hline
\end{tabular}

A large study including 11,550 children from USA, aged between 12 and 19 years, witch explored the association between SHS and lipoprotein cholesterols (total cholesterol, HDL-cholesterol, non-HDL-cholesterol, LDL-cholesterol, and triglycerides), showed that SHS exposure associated higher total cholesterol, higher LDL-cholesterol and lower HDL-cholesterol [13], correlation which, in our study, was significant only regarding HDL- $\mathrm{C}(\mathrm{p}=0.034)$.

The HDL-cholesterol level was lower in children with SHS, $38.36 \mathrm{mg} \%$ compared to controls with a level of $50.44 \mathrm{mg} \%$ (Figure 1) showing the difference of the values which can associate in future a significant cardiovascular risk like many researchers stated [5, 14 ].

\section{The average HDL-cholesterol values within the studied groups}

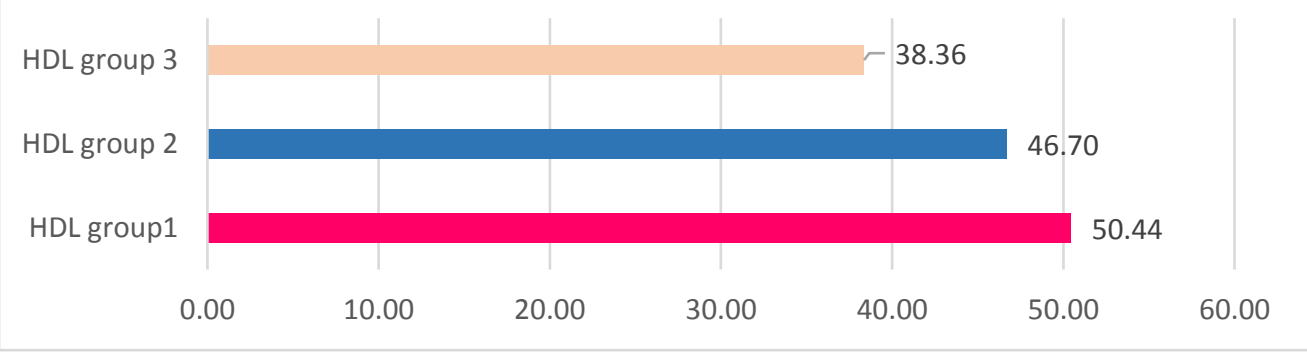

Figure 1. HDL-cholesterol means values in the three studied groups 
HDL-cholesterol was significantly decreased in patients exposed to the passive smoking; witch associates a well-known cardiovascular risk, because an increase HDL-C level has a protective effect on the cardiovascular risk [1,4]. Although lipids and total cholesterol are considered important parameters for cardiovascular risk like smoking [13, 14 ], we did not find an influence with statistical significance of the SHS on serum levels of lipids, triglycerides and cholesterol. It is probably because the levels of lipids, cholesterol and triglycerides is influence by endogenous ways of metabolism and other factors like diet, life style, stress which would be different compared to other studies and biased by the reduced study number of children included. After the statistical analysis we noticed that passive smoking is responsible for alterations in the young patient's biochemical markers but the observed differences were not statistically significant for lipids, total cholesterol and LDL-C, only for HDL-C.

\section{Conclusions}

HDL-cholesterol was significantly decreased in children exposed to the passive smoking in our study, which associates a well-known future cardiovascular risk among children. Although lipids and total cholesterol are considered important parameters for cardiovascular risk like smoking, we did not find an influence with statistical significance of the SHS on serum levels of lipids, triglycerides and cholesterol. Nevertheless, the safest way to reduce the future cardiovascular risk of the children by increasing the HDL-C protective level is second-hand smoking cessation.

\section{References}

1. ÖBERG M, JAAKKOLA MS, WOODWARD A, PERUGA A, PRÜSS-USTÜN A. Worldwide burden of disease from exposure to second-hand smoke: A retrospective analysis of data from 192 countries. Lancet. 2011 Jan 8;377(9760):139-46. doi: 10.1016/S0140-6736(10)61388-8

2. TALHOUT R, SCHULTS T, FLOREK E, VAN BENTHEM J, WESTER P, OPPERHUIZEN A. Hazardous compounds in tobacco smoke. Int J Environ Res Public Health. 2011;8(2):613-628. doi:10.3390/ijerph8020613

3.HARROD CS, FINGERLIN TE, CHASAN-TABER L, REYNOLDS RM, GLUECK DH, DABELEA D. Exposure to prenatal smoking and early-life body composition: The healthy start study. Obesity. 2015 Jan;23(1):234-41. doi: 10.1002/oby.20924;

4. KHANOLKAR AR, BYBERG L, KOUPIL I. Parental influences on cardiovascular risk factors in Swedish children aged 5-14 years. Eur J Public Health. 2012;22(6):840-7. doi:10.1093/eurpub/ckr180; 5.AYER JG, BELOUSOVA E, HARMER JA, DAVID C, MARKS GB, CELERMAJER DS. Maternal cigarette smoking is associated with reduced high-density lipoprotein cholesterol in healthy 8-year-old children. Eur Heart J. 2011 , 32(19):2446-53. doi: 10.1093/eurheartj/ehr174;

6.VUOLO M, STAF J. Parent and child cigarette use: a longitudinal, multigenerational study. Pediatrics. 2013;132(3):e568-e577. doi:10.1542/peds.2013-0067

7.GRONER JA, HUANG H, NAGARAJA H, KUCK J, BAUER JA. Secondhand Smoke Exposure and Endothelial Stress in Children and Adolescents. Physiol Behav. 2017;176(5):139-48. 8. LEE W, HWANG SH, CHOI H, KIM H. The association between smoking or passive smoking and cardiovascular diseases using a Bayesian hierarchical model: based on the 2008-2013 Korea Community Health Survey. Epidemiol Health. 2017;39:e2017026.

9.KONDO T, NAKANO Y, ADACHI S, MUROHARA T. Effects of tobacco smoking on cardiovascular disease. Circ J. 2019;83(10):1980-5.

10. KELISHADI R, NOORI A, QORBANI M, RAHIMZADEH S, DJALALINIA S, SHAFIEE G, et al. Are active and passive smoking associated with cardiometabolic risk factors in adolescents? The CASPIAN-III Study. Paediatr Int Child Health. 2016, 36:3, 181-188,

DOI: 10.1179/2046905515Y.0000000039; 
11. KONISHI H, WU J, COOKE JP. Chronic exposure to nicotine impairs cholinergic angiogenesis. Vasc Med. 2010, 15(1):47-54. doi: 10.1177/1358863X09106326;

12. ANDERSSON K, ARNER P. Systemic nicotine stimulates human adipose tissue lipolysis through local cholinergic and catecholaminergic receptors. Int J Obes. 2001; 25(8):1225-32.;

13. MERIANOS AL, JANDAROV RA, KHOURY JC, MAHABEE-GITTENS EM. Tobacco Smoke Exposure Association With Lipid Profiles and Adiposity Among U.S. Adolescents. J Adolesc Heal. 2018 ; 62(4):463-470. doi: 10.1016/j.jadohealth.2017.10.001

14. TROFOR A, PETRIS O, TROFOR L, MAN, M. A, FILIPEANU D, MIRON R. Biochemistry in assessing tobacco exposure -smokers versus non-smokers: Correlations with clinical practice. Rev Chim. 68(5), 2017, 1002-1006

$\overline{\text { Manuscript received: } 12.12 .2019}$ 